\title{
Reducing antibiotic prescribing for children with respiratory tract infections in primary care:
}

\author{
a systematic review
}

\begin{abstract}
Background

Respiratory tract infections (RTIs) in children are common and often result in antibiotic prescription despite their typically self-limiting course
\end{abstract}

Aim

To assess the effectiveness of primary care based interventions to reduce antibiotic prescribing for children with RTIs.

\section{Design and setting \\ Systematic review.}

\section{Method}

MEDLINE ${ }^{\oplus}$, Embase, CINAHL ${ }^{\oplus}$, PsycINFO, and the Cochrane library were searched for randomised, cluster randomised, and nonrandomised studies testing educational and/or behavioural interventions to change antibiotic prescribing for children ( $<18$ years) with RTIs. Main outcomes included change in proportion of total antibiotic prescribing or change in 'appropriate' prescribing for RTIs. Narrative analysis of included studies was used to identify components of effective interventions.

\section{Results}

Of 6301 references identified through

database searching, 17 studies were included. Interventions that combined parent education with clinician behaviour change decreased antibiotic prescribing rates by between $6-21 \%$; structuring the parent-clinician interaction during the consultation may further increase the effectiveness of these interventions. Automatic computerised prescribing prompts increased prescribing appropriateness, while passive information, in the form of waiting room educational materials, yielded no benefit.

\section{Conclusion}

Conflicting evidence from the included studies found that interventions directed towards parents and/or clinicians can reduce rates of antibiotic prescribing. The most effective interventions target both parents and clinicians during consultations, provide automatic prescribing prompts, and promote clinician leadership in the intervention design.

\section{Keywords}

anti-bacterial agents, children, prescriptions, primary health care, respiratory tract infections.

\section{INTRODUCTION}

Respiratory tract infections (RTIs) in children are common and costly conditions for families, healthcare providers, and health systems. ${ }^{1}$ Clinicians frequently prescribe antibiotics for RTIs, ${ }^{2}$ despite the fact that most are self-limiting and use of antibiotics for most RTIs is of uncertain value. ${ }^{3}$ Overuse of antibiotics is associated with development of antimicrobial resistance, ${ }^{4}$ increased care-seeking behaviour, ${ }^{5}$ and adverse effects. ${ }^{6}$ Perhaps the greatest threat to public health comes from the continuing emergence of antimicrobial resistance. This leads to increased use of second/third generation antibiotics, costlier treatment, and further bacterial resistance.

Efforts to reduce antibiotic prescribing have been ongoing for decades, ${ }^{7}$ and have included a wide range of strategies and campaigns targeted at patients, clinicians, practices, and whole populations. To some extent these efforts have been successful, leading to reductions in the UK of $24 \%$, from 572 antibiotic prescriptions per 1000 child-years in 1996 to 435 prescriptions per 1000 child-years in 2000. ${ }^{8}$ However, US data indicates that while overall antibiotic prescription rates decreased during the 1990s, prescribing rates of broad spectrum

TA Vodicka, research associate; M Thompson, DPhil, MRCGP, clinical reader; C Heneghan, DPhil, MRCGP, clinical reader, Department of Primary Care Health Sciences, University of Oxford, Oxford. P Lucas, PhD, senior lecturer, School for Policy Studies; PS Blair, BSc, MSc, $\mathrm{PhD}$, senior research fellow; N Redmond, BSc, PhD, SCOOP Trial Co-ordinator, TARGET Research Programme Manager; AD Hay, MRCP, DCH, MRCGP, DFFP, FHEA, reader in primary health care, Centre for Academic Primary Care, School of Social and Community Medicine, University of Bristol, Bristol. DI Buckley, MD, assistant professor research, Departments of Family Medicine, Clinical Epidemiology, and Public Health, Oregon Health and Science University. On antibiotics for children with RTls actually increased. Prescribing rates for nonspecific RTIs in the UK have increased by $10 \%$ since $2002 .{ }^{8}$ This upward trend is concerning in light of evidence-based practice recommendations that propose a 'wait and see' approach for the majority of RTIs.

A recent review of interventions to modify parental help-seeking behaviour for RTIs in children found that interventions that engaged children in addition to parents and provided specific symptom guidance were effective at influencing consulting behaviour. ${ }^{10}$ However, strategies are also needed to help clinicians determine which children are most in need of antibiotics, ${ }^{11}$ and reduce inappropriate antibiotic prescribing. ${ }^{12,13}$ Given the importance of the parent-clinician interaction in guiding antibiotic use, this study aimed to systematically review the effectiveness of educational or behavioural interventions directed to parents, clinicians, or both, to reduce antibiotic prescribing for children with RTIs in primary care.

\section{METHODS}

MEDLINE ${ }^{\circledR} /$ PubMed, CINAHL $^{\circledR}$, Embase, PsycINFO and the Cochrane Library

behalf of the TARGET Programme team

\section{Address for correspondence}

Matthew Thompson, Department of Primary Care Health Sciences, University of Oxford, New Radcliffe house, Woodstock Road, Oxford, OX1 2ET.

E-mail: matthew.thompsonaphc.ox.ac.uk Submitted: 6 November 2012; Editor's response: 26 November 2012; final acceptance: 8 January 2013

\section{CBritish Journal of General Practice}

This is the full-length article (published online $1 \mathrm{Jul}$ 2013) of an abridged version published in print. Cite this article as: Br J Gen Pract 2013; DOI: 10.3399/bjgp13X669167 


\section{How this fits in}

Prescribing rates of antibiotics for RT in children have declined, but are still high and largely unnecessary. Reducing unnecessary prescriptions is a priority in order to reduce inappropriate antibiotic use in primary care. Based on a systematic review of 17 studies it was found that the most effective interventions target both parents and clinicians during consultation, provide automatic prescribing prompts, and promote clinician leadership in the intervention design. These can produce significant reductions in antibiotic prescribing for children with RTIs.

(from inception through June 2012) were searched using terms for RTIs, children, parents, education, antibiotic prescription, and consultation (Table 1). One author screened titles and abstracts based on predefined inclusion criteria to identify relevant studies and reviewed reference lists and related citations of selected studies to identify additional references. Two authors reviewed the full-text of selected studies to determine inclusion. Disagreements were settled through discussions with a third author.

Controlled studies were included that used a randomised, cluster randomised, non-randomised or one-group pre- and post- test design to assess the effectiveness of educational or behavioural interventions to change clinicians' antibiotic prescribing for acute RTIs in children (birth to 18 years) in primary care settings (family practice, emergency, or paediatric primary care). Outcomes of interest were change in proportion of antibiotic prescriptions issued for RTls in children, or change in 'appropriate' antibiotic prescribing Comparisons included no-treatment or alternate treatment controls. Studies were excluded if they were: from in-patient settings; evaluations of treatment guidelines, public health interventions diagnostic tests; studies of children with chronic illnesses or serious comorbidities; or studies from countries not classified as high-income by the Organisation for Economic Co-operation and Development.

Two reviewers used an extraction form developed for a previous systematic review ${ }^{10}$ to independently extract data for study design, setting, patient population, intervention, comparison, outcome(s), and assessment method. Disagreements were resolved by discussion with a third author. Reviewers were not blinded to any aspect of the studies. Data from a French language study were extracted following translation.

Two reviewers independently assessed study quality using a framework adapted from the Cochrane handbook. ${ }^{14}$ Randomised or cluster randomised trials were assessed based on randomisation, blinding, description of intervention, exposure to intervention, and generalisability. Non-randomised controlled trials were assessed on the basis of comparability of groups, intervention description, exposure to intervention, and generalisability. One-group designs were assessed based on intervention description, exposure to intervention, and generalisability. A judgement of 'low', 'high', or 'unclear' was made regarding the risk of bias for each criterion; based on this, each study was then given an overall judgement of 'low', 'moderate', or 'high' risk of bias (Table 2). Overall quality assessments were used to interpret the findings.

Mean differences were calculated with 95\% confidence intervals (Cl) for changes in mean numbers of prescriptions, and odds ratios (OR) with $95 \% \mathrm{Cl}$ for changes in prescribing rates, using Yates's correction and Fisher's exact test where an expected cell was below five (Epilnfo version 3.4.3). Where raw data were unavailable, proportional or mean differences were presented. Considerable statistical and clinical heterogeneity prevented pooling of outcomes; therefore results of each study are presented individually and interpreted using narrative analysis.

\section{RESULTS}

Of the 6301 references returned in the search, 17 studies met inclusion criteria (Figure 1). ${ }^{15-31}$ One study ${ }^{21}$ included three different interventions (targeting parents, clinicians, or both) for a total of 19 interventions among the 17 studies. Thirteen studies involved 228 practices or clinics (four studies $15,18,21,31$ did not report number of included practices). The studies varied in design, paediatric population, and length of follow-up (Table 1). The majority of studies used a randomised design ( $n=12)$, with the remaining studies using pre- and post-test ( $n=3)$ or non-randomised designs $(n=2)$. Most were conducted in the US I $n=$ $10)$, followed by Israel $(n=3)$, Europe $(n=3)$, and Australia $(n=1)$. The interventions were delivered in family practice or paediatric care settings, except for one set in an afterhours clinic. ${ }^{23}$ The majority of interventions ( $n=10$ ) were directed toward clinicians and parents. ${ }^{15-24}$ Six interventions were 


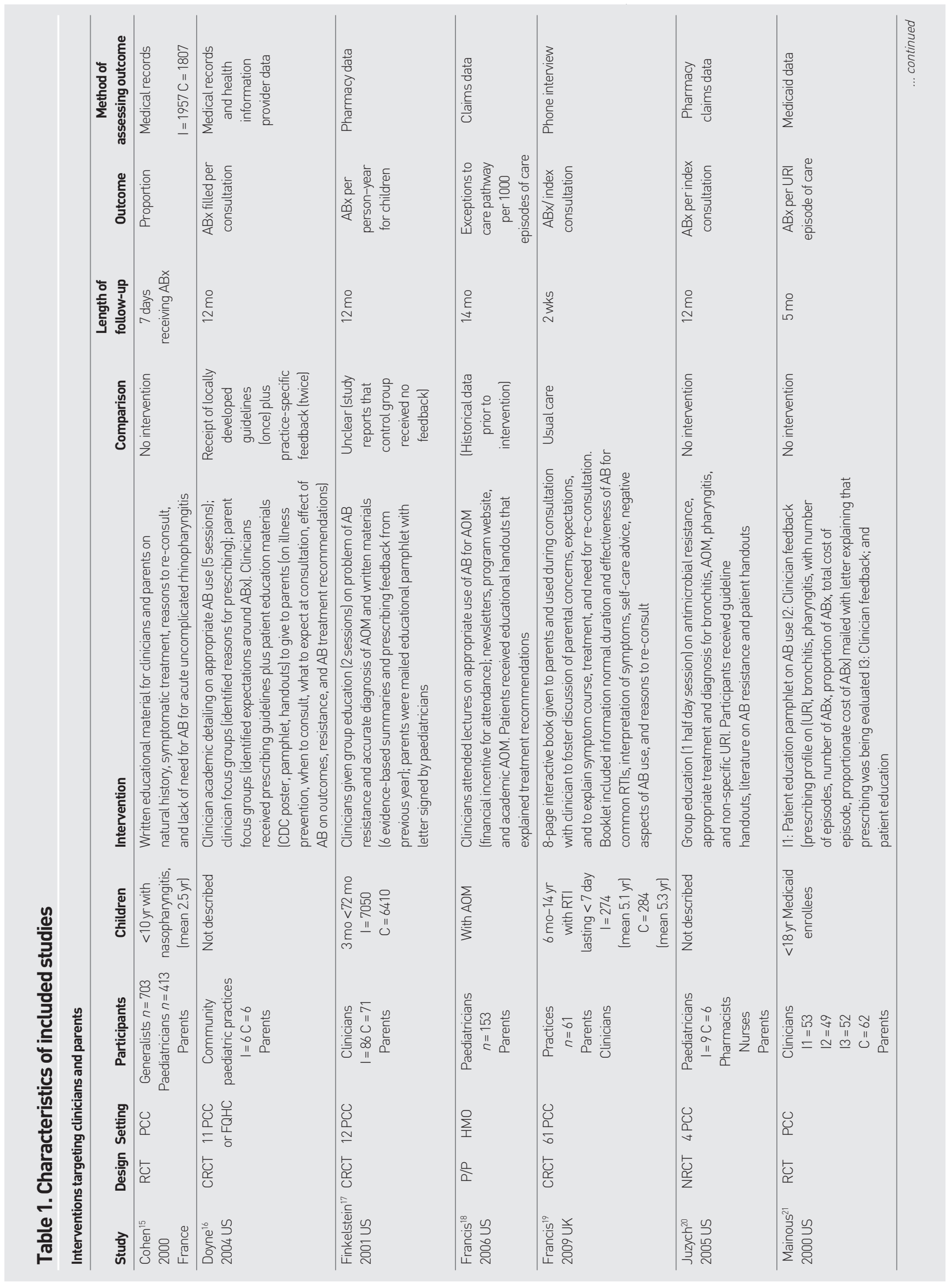




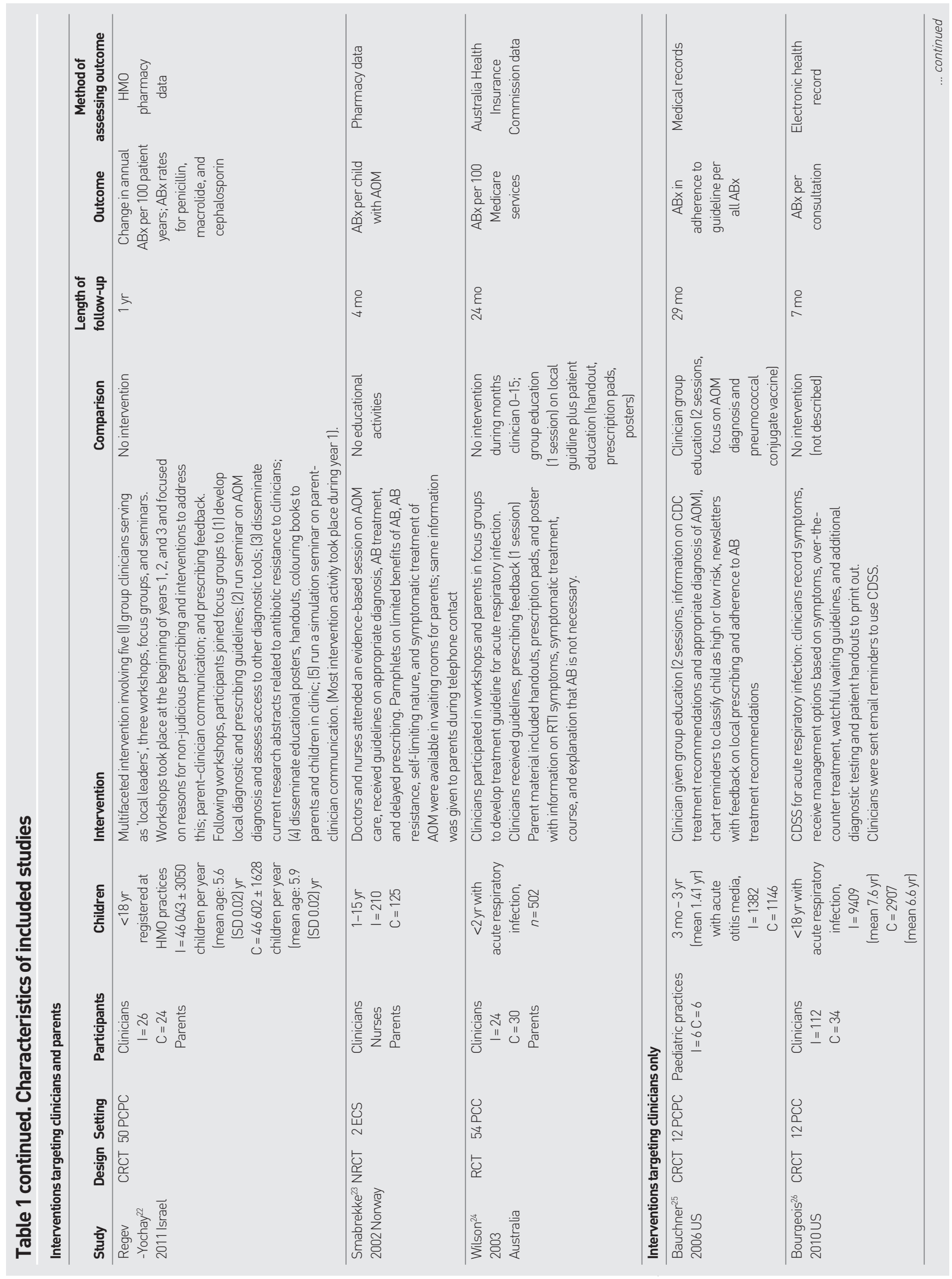




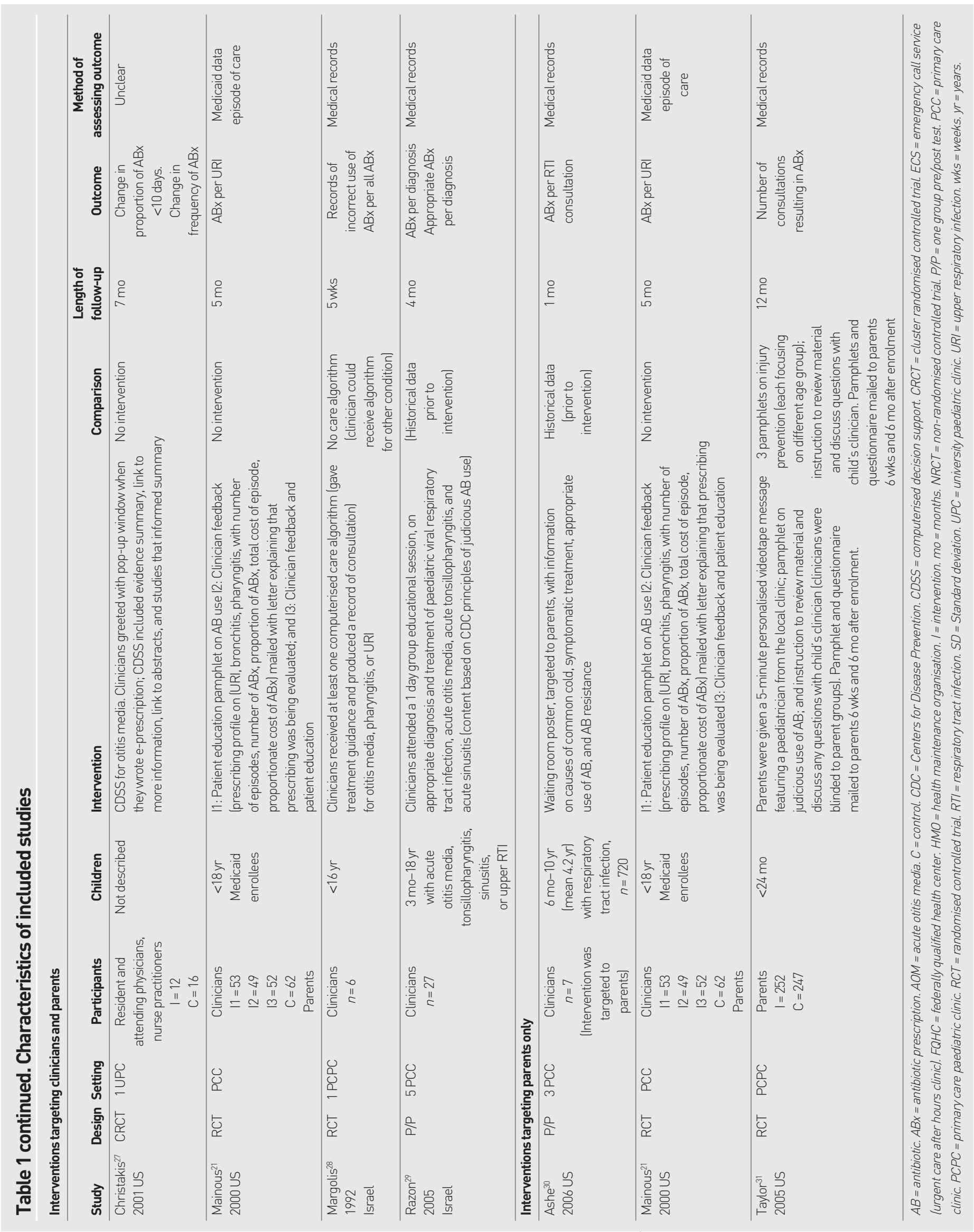


Table 2. Effects of interventions targeting clinicians and parents to reduce antibiotic prescribing for respiratory tract infections in children

\begin{tabular}{|c|c|c|c|c|c|c|c|c|c|}
\hline Study & Age & Outcome & Intervention & Control & $\begin{array}{l}\text { OR }[95 \% \mathrm{Cl}] \\
\text { or } \% \text { difference }\end{array}$ & NNT & $\begin{array}{c}\text { Mean } \\
\text { difference }\end{array}$ & Significance & $\begin{array}{l}\text { Risk of } \\
\text { bias }\end{array}$ \\
\hline Cohen ${ }^{15} 2000$ & $<10 y r$ & Proportion receiving $\mathrm{ABx}$ & $523 / 1957(26.7 \%)$ & 670/1807 (37.1\%) & 0.62 [0.54 to 0.75$]$ & 10 & - & $<0.001$ & Moderate \\
\hline Finkelstein ${ }^{17}$ & 3 to $<36 \mathrm{mo}$ & Change in $\mathrm{ABx} /$ person-year & $-18.6 \%$ & $-11.5 \%$ & $7.1 \%$ & - & - & $<0.001$ & Moderate \\
\hline $2001^{a, b}$ & 36 to $<72 \mathrm{mo}$ & & $-15 \%$ & $-9.8 \%$ & $5.2 \%$ & - & - & $<0.001$ & \\
\hline Francis $^{18} 2006^{c}$ & NR & Exceptions to care pathway & $33.7 \%$ & $41.2 \%$ & $7.5 \%$ & 13 & & $<0.001$ & Moderate \\
\hline Francis $^{19} 2009^{a}$ & $6 \mathrm{mo}-14 \mathrm{yr}$ & ABx/index consultation & $50 / 256(19.5 \%)$ & $111 / 272(40.8 \%)$ & 0.35 [0.23 to 0.53] & 5 & - & $<0.001$ & Minimum \\
\hline Juzych $202005^{b, d}$ & NR & Change in $\mathrm{ABx} /$ consultation & $-25.9 \%$ & $-4.8 \%$ & $21.1 \%$ & - & - & $\begin{array}{l}\text { I: }<0.0001 e \\
\text { C: } 0.355^{e}\end{array}$ & Moderate \\
\hline Mainous $^{21} 2000^{b}$ & $b^{b}<18 y r$ & $\begin{array}{l}\text { Mean change in proportion of } \\
\text { consultations resulting in } \mathrm{ABx}\end{array}$ & $15.3 \%$ & $22.5 \%$ & - & - & $7.2 \%$ & $<0.05$ & Moderate \\
\hline $\begin{array}{l}\text { Regev-Yochay }{ }^{22} \\
2011^{\text {a }}\end{array}$ & $<18 y r$ & $\begin{array}{c}\text { ABx/100 patient-years }(n) \\
\text { Year 0, baseline } \\
\text { Year 1, baseline } \\
\text { Year 2, intervention } \\
\text { Year 3, intervention } \\
\text { Year 4, intervention } \\
\text { Year 5, follow-up }\end{array}$ & $\begin{array}{l}78.38 \text { (43 677) } \\
65.57 \text { (44 702) } \\
46.93 \text { (42 495) } \\
48.18 \text { (46 046) } \\
48.99 \text { (49 341) } \\
45.91 \text { (49 998) }\end{array}$ & $\begin{array}{l}76.32 \text { (44 453) } \\
70.95 \text { (45 195) } \\
59.34 \text { (45 918) } \\
57.58 \text { (48 023) } \\
59.60 \text { (48 323) } \\
54.56 \text { (47 701) }\end{array}$ & $\begin{array}{l}1.116[0.91 \text { to } 1.36] \\
0.914[0.89 \text { to } 0.93] \\
0.765[0.75 \text { to } 0.78] \\
0.809[0.79 \text { to } 0.83] \\
0.809[0.79 \text { to } 0.83] \\
0.844[0.82 \text { to } 0.86]\end{array}$ & $\begin{array}{l}- \\
- \\
- \\
- \\
-\end{array}$ & $\begin{array}{l}- \\
- \\
- \\
- \\
-\end{array}$ & $\begin{array}{l}- \\
- \\
- \\
- \\
-\end{array}$ & Moderate \\
\hline $\begin{array}{l}\text { Smabrekke }{ }^{23} \\
2002^{d}\end{array}$ & $1-15 y r$ & $\begin{array}{l}\text { Patients receiving } A B x \text { of those } \\
\text { consulting with acute otitis media }\end{array}$ & $155 / 210(73.8 \%)$ & $114 / 124(91.9 \%)$ & 0.25 [0.11 to 0.53] & 6 & - & $<0.001$ & Moderate \\
\hline $\begin{array}{l}\text { Wilson }^{24} \\
2003^{b}\end{array}$ & $<2 \mathrm{yr}$ & $\begin{array}{l}\text { Mean change in ABx/ } \\
100 \text { Medicare services }\end{array}$ & $-0.78(+-1.3)$ & $0.35(+-1.7)$ & - & - & 1.13 & 0.03 & Moderate \\
\hline \multicolumn{10}{|c|}{$\begin{array}{l}{ }^{a} \text { Cluster randomised controlled trial. }{ }^{b} \text { No absolute numbers given. }{ }^{c} \text { Pre- and post- design: intervention }=\text { post; control }=\text { pre. }{ }^{d} \text { Non-randomised controlled trial. }{ }^{e} \text { Within-group } \\
\text { significance. } A B x=\text { antibiotic prescriptions. } m o=\text { month. NNT =Number needed to treat. NR = not reported. NS = not significant. yr }=y e a r . \text { Italicised P-values were those reported } \\
\text { in original study. }\end{array}$} \\
\hline
\end{tabular}

directed toward clinicians only; ${ }^{21,25-29}$ three interventions targeted parents only. 21,30-31

\section{Effects of interventions targeting} clinicians and parents

Eight of the 10 interventions which targeted

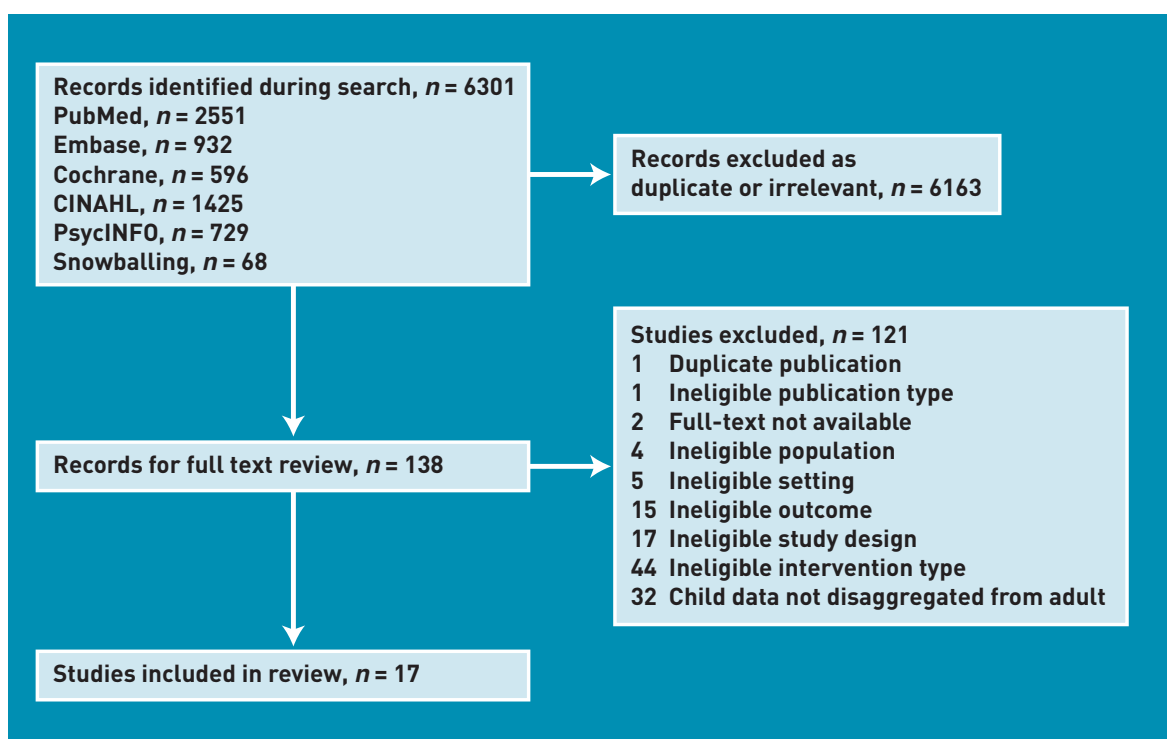

significantly decreased prescribing rates, ${ }^{15,17-20,22-24}$ with reductions ranging from $6-21 \%$ at follow-up from 1 week $^{15}$ to 2 years $^{24}$ (Table 2). The largest effect was observed in a study which used a combined parent-clinician 'interactive book' during the consultation, resulting in a lower prescribing rate of $19.5 \%$ lversus $40.8 \%$, $P<0.001$ l) at 2 weeks. ${ }^{19}$ One intervention, a combination of academic detailing and written parent education, showed no effect. ${ }^{16}$ The remaining study by Mainous et al reported increased rates of antibiotic prescribing in both intervention (15.3\%) and control groups (22.5\%) during the 5-month study period. ${ }^{21}$

Most studies had a moderate risk of bias due to poor reporting of methods or uncertain participant exposure to the intervention. 16-18,20,21,23,24 The method of randomisation was not reported in either study where there was no intervention effect. $^{16,21}$ Indeed, Doyne et al noted that the lack of effect could in part be due to dissimilar prescribing rates between groups at baseline and to concurrent media campaigns. ${ }^{16}$

Three studies reported adverse events 
Table 3. Effects of interventions targeting clinicians to reduce antibiotic prescribing for respiratory tract infections in children

\begin{tabular}{|c|c|c|c|c|c|c|c|c|c|}
\hline Study & Age & Outcome & Intervention & Control & $\begin{array}{l}\text { OR }[95 \% \mathrm{Cl}] \\
\text { or difference }\end{array}$ & NNT & $\begin{array}{c}\text { Mean } \\
\text { difference }\end{array}$ & Significance & $\begin{array}{l}\text { Risk of } \\
\text { bias }\end{array}$ \\
\hline $\begin{array}{l}\text { Bauchner }^{25} \\
2006^{\text {a }}\end{array}$ & $3 \mathrm{mo}-3 \mathrm{yr}$ & $\begin{array}{l}\text { ABx in adherence to guideline/total ABx } \\
\text { First episode of acute otitis media } \\
\text { Second episode of acute otitis media }\end{array}$ & $\begin{array}{l}1073 / 1373(78.2 \%) \\
316 / 505(62.6 \%)\end{array}$ & $\begin{array}{c}795 / 1126(70.6 \%) \\
248 / 414(60 \%)\end{array}$ & $\begin{array}{l}1.49[1.24 \text { to } 1.79] \\
1.12[0.85 \text { to } 1.47]\end{array}$ & $\begin{array}{l}13 \\
37\end{array}$ & - & $\begin{array}{l}0.42^{d} \\
0.84^{d}\end{array}$ & Moderate \\
\hline $\begin{array}{l}\text { Bourgeois }{ }^{26} \\
2010^{\mathrm{b}}\end{array}$ & $<18 y r$ & ABx/RTI consultation & $5929 / 14934$ (39.7\%) & $2303 / 5007(46 \%)$ & $6.3 \%$ & - & - & $0.844^{\mathrm{d}}$ & Moderate \\
\hline $\begin{array}{l}\text { Mainous }^{21} \\
2000^{c}\end{array}$ & $<18 y r$ & $\begin{array}{l}\text { Mean change in proportion of } \\
\text { consultations resulting in } A B x\end{array}$ & $15.2 \%$ & $22.5 \%$ & - & - & $7.3 \%$ & NS & Moderate \\
\hline $\begin{array}{l}\text { Margolis }{ }^{28} \\
1992^{c}\end{array}$ & $<16 y r$ & $\begin{array}{c}\text { Incorrect AB orders/all AB orders } \\
\text { Otitis media } \\
\text { Pharyngitis } \\
\text { Upper respiratory infection }\end{array}$ & $\begin{array}{l}12 \% \\
18 \% \\
44 \%\end{array}$ & $\begin{array}{l}46 \% \\
47 \% \\
64 \%\end{array}$ & $\begin{array}{l}34 \% \\
29 \% \\
20 \%\end{array}$ & $\begin{array}{l}- \\
- \\
-\end{array}$ & $\begin{array}{l}- \\
- \\
-\end{array}$ & $\begin{array}{c}<0.001 \\
<0.01 \\
N S\end{array}$ & Moderate \\
\hline $\begin{array}{l}\text { Razon }^{29} \\
2005^{b}\end{array}$ & $3 \mathrm{mo}-18 \mathrm{yr}$ & $\begin{array}{c}\text { Appropriate } \mathrm{ABx} / \text { consultations } \\
\text { Acute otitis media } \\
\text { Pharyngitis/tonsillitis } \\
\text { Sinusitis } \\
\mathrm{ABx} / \text { consultations } \\
\text { Acute otitis media } \\
\text { Pharyngitis/ tonsillitis } \\
\text { Sinusitis } \\
\text { Upper respiratory infection }\end{array}$ & $\begin{array}{c}1784 / 2114(84.4 \%) \\
711 / 1434(49.6 \%) \\
108 / 186(58.1 \%) \\
\\
1848 / 2114(87.4 \%) \\
1196 / 1434(83.4 \%) \\
160 / 186(86 \%) \\
97 / 846(11.5 \%)\end{array}$ & $\begin{array}{c}1290 / 1727(74.7 \%) \\
654 / 1610(40.6 \%) \\
91 / 166(54.8 \%) \\
1606 / 1727(92.9 \%) \\
1348 / 1610(83.7 \%) \\
143 / 166(86.1 \%) \\
119 / 861(13.8 \%)\end{array}$ & $\begin{array}{l}0.52[0.42 \text { to } 0.66] \\
0.98[0.80 \text { to } 1.19] \\
0.99[0.52 \text { to } 1.89] \\
0.81[0.60 \text { to } 1.09]\end{array}$ & $\begin{array}{c}18 \\
309 \\
813 \\
43\end{array}$ & $\begin{array}{l}- \\
- \\
-\end{array}$ & $\begin{array}{c}<0.001 \\
<0.001 \\
0.61 \\
<0.001 \\
0.85 \\
0.90 \\
0.16\end{array}$ & Moderate \\
\hline
\end{tabular}

${ }^{a}$ Cluster randomised controlled trial. ${ }^{b}$ Pre/post design: intervention $=$ post; control = pre. ${ }^{c}$ No absolute numbers given. ${ }^{d}$ Adjusted for cluster randomization. $A B=$ antibiotic. ABx $=$

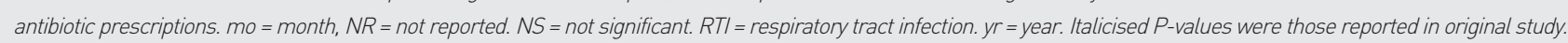

or re-consultation rates, and reported no difference in rates of mastoiditis ${ }^{23}$ or re-consultations. ${ }^{19,20}$ Cohen et al found no significant difference in symptom duration between groups despite a significantly lower rate of antibiotic prescription $(26.7 \%$ versus $37.1 \%, P<0.001)$ in the intervention group..$^{15}$

\section{Effects of interventions targeting} clinicians only

Of the six interventions targeted only to clinicians, one ${ }^{29}$ reported a significant reduction in antibiotic prescribing, and a further $t_{w}{ }^{27,28}$ reported significant reductions in inappropriate prescribing (Table 3). The remaining three studies found either no significant reduction or an increase in antibiotic prescribing. $21,25,26$

Razon et al studied the effect of a 1-day educational seminar for clinicians and found significant reductions in antibiotic prescriptions per diagnosis at 4 months for acute otitis media lOR $0.52[95 \% \mathrm{Cl}=0.42$ to 0.66$]$ ), but not for pharyngitis/tonsillitis,

Table 4. Effects of interventions targeting parents to reduce antibiotic prescribing for respiratory tract infections in children

\begin{tabular}{|c|c|c|c|c|c|c|c|c|c|}
\hline Study & Age & Outcome & Intervention & Control & $\begin{array}{l}\text { OR }[95 \% \mathrm{Cl}] \\
\text { or difference }\end{array}$ & NNT & $\begin{array}{c}\text { Mean } \\
\text { difference }\end{array}$ & Significance & $\begin{array}{l}\text { Risk of } \\
\text { bias }\end{array}$ \\
\hline $\begin{array}{l}\text { Ashe }^{30} \\
2006^{a}\end{array}$ & $6 \mathrm{mo}-10 \mathrm{yr}$ & ABx/RTI consultation & $151 / 360(41.9 \%)$ & $175 / 360$ (48.6\%) & $0.76[0.56$ to 1.04$]$ & 15 & - & 0.09 & Low \\
\hline $\begin{array}{l}\text { Mainous }^{21} \\
2000^{\mathrm{b}}\end{array}$ & $<18 y r$ & $\begin{array}{l}\text { Mean change in proportion of } \\
\text { consultations resulting in } A B x\end{array}$ & $12.6 \%$ & $22.5 \%$ & - & - & $9.9 \%$ & $<0.05$ & Moderate \\
\hline $\begin{array}{l}\text { Taylor }{ }^{31} \\
2005\end{array}$ & $<24 \mathrm{mo}$ & $\begin{array}{c}\text { Number of visits with } \mathrm{AB} x \text { for } \mathrm{OM}^{c} \\
\text { Number of visits with } \mathrm{AB} \text { x for } \mathrm{OM} \\
\text { or sinusitis }\end{array}$ & $\begin{array}{l}1.7 \pm 2.1 \\
1.9 \pm 2.3\end{array}$ & $\begin{array}{l}1.9 \pm 2.4 \\
2.1 \pm 2.5\end{array}$ & - & - & $\begin{array}{l}0.2 \\
0.2\end{array}$ & $\begin{array}{l}0.23 \\
0.24\end{array}$ & Low \\
\hline
\end{tabular}


sinusitis or undefined upper respiratory infection. ${ }^{29}$ Using a computer decision support system (CDSS) that automatically began each time a clinician wrote an antibiotic prescription, Christakis et al reported a 34\% reduction in the frequency of inappropriate prescribing (prescriptions for $>10$ days); however, the prescribing rate increased overall during the 7-month follow-up, though to a lesser extent in the intervention group $14.3 \%$ versus $16.8 \%$, non-significant). ${ }^{27}$ Margolis et al found significant decreases in rates of "incorrect antibiotic prescribing for otitis media (34\%) and pharyngitis (29\%) but not upper respiratory infections among clinicians using a computerised algorithm, however, the study was stopped prematurely due to low participation. ${ }^{28}$

Prescribing feedback reports did not reduce prescribing, in fact rates increased by $15.2 \%$ at 5 months (versus $22.5 \%$ among controls). ${ }^{21}$ Interventions in two other studies that did not find significant reductions in prescribing included an optional $\mathrm{CDSS}^{26}$ (in contrast to the automatic system in the Christakis studyl, and prescribing feedback reports coupled with group education sessions. ${ }^{25}$

All studies in this group presented a moderate risk of bias due to unclear methods, ${ }^{21,25,26,28}$ uncertain or low exposure to the intervention, ${ }^{21,25,26,28}$ lack of detail in the intervention description, ${ }^{21,28}$ or lack of control group..$^{29}$

\section{Effects of interventions targeting parents only}

None of the interventions directed only at parents significantly reduced antibiotic prescribing (Table 4). ${ }^{21,30-31}$ Ashe et al reported that a waiting room poster with information on judicious antibiotic use did not produce a significant difference in prescribing rates between intervention and control groups $141.9 \%$ versus $48.6 \%$, $P=0.09) .{ }^{30}$ Testing the effect of patient education pamphlets, Mainous et al observed an overall $12.6 \%$ increase in prescribing over 5 months, although this was lower than the increase seen in the control group (22.5\%)..21 In the study by Taylor et al, parents viewed a brief videotape message and received a pamphlet 6 weeks and 6 months after initial randomisation (materials included education about the judicious use of antibiotics); at 12 months there was no significant difference in the number of RTI consultations resulting in antibiotic prescription between groups. ${ }^{31}$ The studies by Ashe and Taylor had a low risk of bias, whereas the Mainous study had a moderate risk of bias due to unclear methods and intervention description. No study assessed extent of exposure to the intervention.

\section{DISCUSSION}

\section{Summary}

Conflicting evidence from the 17 studies found that interventions directed towards parents and/or clinicians can reduce rates of antibiotic prescribing for children with RTIs. The most effective interventions involved targeting both parents and clinicians during a consultation, ${ }^{19}$ providing automatic computer prompts for evidencebased prescribing, ${ }^{27}$ and promoting clinician leadership or participation in the design of treatment guidelines and/or peer education. 22,24 There was moderately strong evidence that interventions were more effective in reducing antibiotic prescribing when delivered to clinicians in collaboration with parents. ${ }^{15,17-19,22-24}$ In contrast, based on limited evidence, passive strategies targeting only parents, such as waiting room posters or pamphlets, do not appear to alter prescribing rates significantly. ${ }^{30-31}$ Moreover, interventions involving printed materials for parents varied in effect; those with actionable information (such as self-care advice and signs to re-consult) ${ }^{18}$ were more effective in reducing rates of antibiotic prescription than materials with generic information on the appropriate use of antibiotics. ${ }^{30}$ The findings suggest computer-based interventions are only successful when integrated into routine clinical processes (for example, writing prescriptions) and less so when clinicians must manually employ the application.

\section{Strengths and limitations}

Only published studies were included therefore unpublished studies of relevant interventions may have been missed. To address risk of publication bias multiple databases were searched, the search by language was not limited, and reference lists and related citations of included studies were also searched. The focus was on studies from high income countries, which may limit the generalisability of the findings to low/middle income settings. Overall methodological quality of the included studies was highly variable and generally moderate. Most studies did not report the extent of parent and/or clinician completion or participation in intervention activities; this risk of bias may further limit the robustness of conclusions that can be drawn from the reported findings. Studies which assess 'appropriate' prescribing 
could be subject to changes in diagnostic labelling by participating clinicians, which would bias the results toward a positive intervention effect. ${ }^{32} \mathrm{Also}$, diagnostic criteria for eligible RTIs were not clearly described, and it is unclear how generalisable the spectrum of illness was in study populations at enrolment. Only three studies reported complications or re-consultations; results from these studies did not indicate increased risk of adverse events related to decreased prescribing but would not have been adequately powered to identify effects on less common adverse outcomes (for example, hospital admission). ${ }^{19,20,23}$

\section{Comparison with existing literature}

Previous reviews have explored the effectiveness of interventions to change antibiotic prescribing behaviour of clinicians for various types of infection in adults and children. ${ }^{13,33-35}$ These reviews and prior research similarly concluded that the most effective interventions involve clinicians and patients, ${ }^{35-37}$ as well as the general public.7.32 In a systematic review of antimicrobial control programmes in paediatric outpatient and hospital settings lof which four studies overlap with this review) Patel et al concluded that provider-targeted interventions which featured diagnosis-specific education were more likely to change prescribing for childhood infections. ${ }^{34}$ Two systematic reviews (Arnold ${ }^{33}$ and Ranjii3) examined effectiveness of clinician and/or parent strategies to reduce antibiotic prescribing for adults and children for all conditions in outpatient settings. Although only a small number of the studies in this review overlapped with these (six out of 30 studies in Ranji; two out of 39 studies in Arnold), the findings broadly concur with their conclusions that effective interventions to reduce antibiotic prescribing involve multifaceted approaches targeting clinicians and patients, and that printed materials or audit and feedback had limited effect.

Finally, a systematic review ${ }^{13}$ of interventions to change health professional's behaviour lincluding prescribing, referral, clinician knowledge, and guideline compliance) in management of children with upper RTIs in any type of setting identified 10 studies (six of which are also included in this review $20,23-25,27,28)$. It concluded that computer interventions, educational sessions, collaboratively developed guidelines and training videos were effective in changing practice, and that multifaceted and computer interventions worked best. This review identified an additional 11 studies specific to antibiotic prescribing for children with RTI in primary care, and included interventions directed towards both clinicians and parents, which more realistically reflects actual practice. Only mixed evidence was found to support CDSS to change clinician behaviour (partly due to the inclusion of a newer study ${ }^{26}$ ) and noted that the more effective CDSS provided: recommendations rather than just assessments; and automatic decision support at the time and location of decisionmaking. ${ }^{38}$ We found two studies including consultation skills training, ${ }^{19,22}$ which has been shown to be effective in reducing antibiotic prescribing for adults. ${ }^{39-40}$

\section{Implications for practice and research}

For policymakers, the findings of this study suggest that more appropriate prescribing for RTIs in children may be achieved when interventions are designed in consultation with participants, incorporate changes into everyday prescribing processes, and address the needs of parents and clinicians. Passive approaches such as waiting room posters and written materials in isolation have limited effects. However, the costeffectiveness of these interventions and effects on other health service outcomes such as repeat attendance or risk of complications need to be determined. In addition, clinicians and parents need evidence for the effectiveness of alternatives to antibiotic therapy for symptomatic relief of RTIs. ${ }^{41}$ Qualitative research, involving parents and clinicians, of the reasons why some interventions are more effective than others could improve the understanding of effective interventions. Ongoing studies involving multi-component interventions, HAPPY AUDIT, ${ }^{42}$ DECISION,$+{ }^{43}$ and TARGET (http://targetstudy.org.uk/), will likely contribute new data to these research gaps.

\section{Acknowledgements}

We gratefully acknowledge the contribution of Dr Jan Verbakel for assistance extracting data from a non-English language study.

\section{Discuss this article}

Contribute and read comments about this article on the Discussion Forum: http://www.rcgp.org.uk/bjgp-discuss 


\section{REFERENCES}

1. Hollinghurst S, Gorst C, Fahey T, Hay AD. Measuring the financial burden of acute cough in pre-school children: a cost of illness study. BMC Fam Pract 2008; 9: 10

2. Hersh AL, Shapiro DJ, Pavia AT, Shah SS. Antibiotic prescribing in ambulatory pediatrics in the United States. Pediatrics 2011; 128(6): 1053-1061.

3. Keith T, Saxena S, Murray J, Sharland M. Risk-benefit analysis of restricting antimicrobial prescribing in children: what do we really know? Curr Opin Infect Dis 2010; 23(3): 242-248.

4. Costelloe $\mathrm{C}$, Metcalfe $\mathrm{C}$, Lovering $\mathrm{A}$, et al. Effect of antibiotic prescribing in primary care on antimicrobial resistance in individual patients: systematic review and meta-analysis. BMJ 2010; 340: c2096.

5. Little P, Gould C, Williamson I, et al. Reattendance and complications in a randomised trial of prescribing strategies for sore throat: the medicalising effect of prescribing antibiotics. BMJ 1997; 315(7104): 350-352.

6. Clavenna A, Bonati M. Adverse drug reactions in childhood: a review of prospective studies and safety alerts. Arch Dis Child 2009; 94(9): 724-728.

7. Huttner B, Goossens H, Verheij T, Harbarth S. Characteristics and outcomes of public campaigns aimed at improving the use of antibiotics in outpatients in high-income countries. Lancet Infect Dis 2010; 10(1): 17-31.

8. Thompson PL, Spyridis N, Sharland M, et al. Changes in clinical indications for community antibiotic prescribing for children in the UK from 1996 to 2006: will the new NICE prescribing guidance on upper respiratory tract infections just be ignored? Arch Dis Child 2009; 94(5): 337-340.

9. Steinman MA, Gonzales R, Linder JA, Landefeld CS. Changing use of antibiotics in community-based outpatient practice, 1991-1999. Ann Intern Med 2003; 138(7): 525-533.

10. Andrews T, Thompson M, Buckley DI, et al. Interventions to influence consulting and antibiotic use for acute respiratory tract infections in children: a systematic review and meta-analysis. PLoS One 2012; 7(1): e30334.

11. Kumar S, Little P, Britten N. Why do general practitioners prescribe antibiotics for sore throat? Grounded theory interview study. BMJ 2003; 326(7381): 138.

12. Kai J. Parents' difficulties and information needs in coping with acute illness in preschool children: a qualitative study. BMJ 1996; 313(7063): 987-990.

13. Boonacker CW, Hoes AW, Dikhoff MJ, et al. Interventions in health care professionals to improve treatment in children with upper respiratory tract infections. Int J Pediatr Otorhinolaryngol 2010; 74(10): 1113-1121.

14. Higgins JPT, Green S (eds). Cochrane handbook for systematic reviews of interventions version 5.1.0 [updated March 2011]. The Cochrane Collaboration, 2011. www.cochrane-handbook.org (accessed 20 May 2013).

15. Cohen R, Allaert FA, Callens A, et al. Medico-economic evaluation of an educational intervention to optimize children uncomplicated nasopharyngitis treatment in ambulatory care. Med Mal Infect 2000; 30: 691-698.

16. Doyne EO, Alfaro MP, Siegel RM, et al. A randomized controlled trial to change antibiotic prescribing patterns in a community. Arch Pediatr Adol Med 2004 158(6): 577-583

17. Finkelstein JA, Davis RL, Dowell SF, et al. Reducing antibiotic use in children: a randomized trial in 12 practices. Pediatrics 2001; 108(1): 1-7.

18. Francis DO, Beckman H, Chamberlain J, et al. Introducing a multifaceted intervention to improve the management of otitis media: how do pediatricians, internists, and family physicians respond? Am J Med Qual 2006; 21(2): 134-143.

19. Francis NA, Butler CC, Hood K, et al. Effect of using an interactive booklet about childhood respiratory tract infections in primary care consultations on reconsulting and antibiotic prescribing: a cluster randomised controlled trial. BMJ 2009; 339: b2885.

20. Juzych NS, Banerjee M, Essenmacher L, Lerner SA. Improvements in antimicrobial prescribing for treatment of upper respiratory tract infections through provider education. J Gen Intern Med 2005; 20(10): 901-905.

21. Mainous AG 3rd, Hueston WJ, Love MM, et al. An evaluation of statewide strategies to reduce antibiotic overuse. Fam Med 2000; 32(1): 22-29.

22. Regev-Yochay G, Raz M, Dagan R, et al. Reduction in antibiotic use following a cluster randomized controlled multifaceted intervention: the Israeli judicious antibiotic prescription study. Clin Infect Dis 2011; 53(1): 33-41.
23. Smabrekke L, Berild D, Giaever A, et al. Educational intervention for parents and healthcare providers leads to reduced antibiotic use in acute otitis media. Scand $J$ Infect Dis 2002; 34(9): 657-659.

24. Wilson EJ, Nasrin D, Dear KB, Douglas RM. Changing GPs' antibiotic prescribing: a randomised controlled trial. Commun Dis Intell Q Rep 2003; 27 Suppl: s32-38.

25. Bauchner H, Marchant CD, Bisbee A, et al. Effectiveness of Centers for Disease Control and Prevention recommendations for outcomes of acute otitis media. Pediatrics 2006; 117(4): 1009-1017.

26. Bourgeois FC, Linder J, Johnson SA, et al. Impact of a computerized template on antibiotic prescribing for acute respiratory infections in children and adolescents. Clin Pediatr (Phila) 2010; 49(10): 976-983.

27. Christakis DA, Zimmerman FJ, Wright JA, et al. A randomized controlled trial of point-of-care evidence to improve the antibiotic prescribing practices for otitis media in children. Pediatrics 2001; 107(2): e15.

28. Margolis CZ, Warshawsky SS, Goldman L, et al. Computerized algorithms and pediatricians' management of common problems in a community clinic. Acad Med 1992; 67: 282-284.

29. Razon Y, Ashkenazi S, Cohen A, et al. Effect of educational intervention on antibiotic prescription practices for upper respiratory infections in children: a multicentre study. J Antimicrob Chemoth 2005; 56(5): 937-940.

30. Ashe D, Patrick PA, Stempel MM, et al. Educational posters to reduce antibiotic use. J Pediatr Health Care 2006; 20(3): 192-197.

31. Taylor JA, Kwan-Gett TSC, McMahon EM Jr. Effectiveness of a parental educational intervention in reducing antibiotic use in children: a randomized controlled trial. Pediatr Infect Dis J 2005; 24(6): 489-493.

32. Stanton N, Francis NA, Butler CC. Reducing uncertainty in managing respiratory tract infections in primary care. Br J Gen Pract 2010; DOI: 10.3399/ bjgp10X544104.

33. Arnold SR, Straus SE. Interventions to improve antibiotic prescribing practices in ambulatory care. Cochrane Database Syst Rev 2005; (4): CD003539.

34. Patel SJ, Larson EL, Kubin CJ, Saiman L. A review of antimicrobial control strategies in hospitalized and ambulatory pediatric populations. Pediatr Infect Dis J 2007; 26(6): 531-537.

35. Ranji SR, Steinman MA, Shojania KG, Gonzales R. Interventions to reduce unnecessary antibiotic prescribing: a systematic review and quantitative analysis. Med Care 2008; 46(8): 847-862.

36. Finch RG, Metlay JP, Davey PG, Baker LJ. Educational interventions to improve antibiotic use in the community: report from the International Forum on Antibiotic Resistance (IFAR) colloquium, 2002. Lancet Infect Dis 2004: 4(1): 44-53.

37. Stille CJ, Rifas-Shiman SL, Kleinman K, et al. Physician responses to a community-level trial promoting judicious antibiotic use. Ann Fam Med 2008; 6(3): 206-212.

38. Kawamoto K, Houlihan CA, Balas EA, Lobach DF. Improving clinical practice using clinical decision support systems: a systematic review of trials to identify features critical to success. BMJ 2005; 330(7494): 765.

39. Cals JWL, Butler CC, Hopstaken RM, et al. Effect of point of care testing for $\mathrm{C}$ reactive protein and training in communication skills on antibiotic use in lower respiratory tract infections: cluster randomised trial. BMJ 2009; 338: b1374.

40. Butler C, Simpson SA, Dunstan F, et al. Effectiveness of multifaceted educational programme to reduce antibiotic dispensing in primary care: practice based randomised controlled trial. BMJ 2012; 344: d8173.

41. Kelley M, Massing MW, Young J, et al. Feasibility of a primary care intervention to decrease oral antibiotics for acute upper respiratory tract infections: a pilot study. NC Med J 2006; 67(4): 249-254

42. Bjerrum L, Munck A, Gahrn-Hansen B, et al. Health Alliance for prudent antibiotic prescribing in patients with respiratory tract infections (HAPPY AUDIT)-impact of a non-randomised multifaceted intervention programme. BMC Fam Pract 2011: 12: 52

43. Légaré F, Labreque M, Godin G, et al. Training family physicians and residents in family medicine in shared decision making to improve clinical decisions regarding the use of antibiotics for acute respiratory infections: protocol for a clustered randomized controlled trial. BMC Fam Pract 2011; 12: 3. 